\title{
Low-Background Nuclear Studies of Uranium/Thorium Components of Sediments of The Tisza River Water Basin
}

\author{
Natalia SVATIUK ${ }^{1}$, Victoria ROMAN ${ }^{1}$, Oksana POP', Olesya SIMKANICH ${ }^{2}$, Volodymyr \\ POLISHCHUK ${ }^{2}$, Oleg GLUKH ${ }^{2}$, Igor PYLYPCHYNETS ${ }^{1}$ and Volodymyr MASLYUK ${ }^{1}$
}

Authors' affiliations and addresses:

${ }^{1}$ Institute of Electron Physic of the National Academy of Sciences of Ukraine, Ukraine,

Uzhhorod, University st., 21.

e-mail: svatiuk@nas.gov.ua

e-mail: viktoriyaroman11@gmail.com

e-mail: oksana_pop@i.ua

e-mail: volodymyr.maslyuk@gmail.com

e-mail: Igor.profi@gmail.com

${ }^{2}$ Uzhhorod National University, Ukraine,

Uzhhorod, Pidhirna st., 46

e-mail: olesjasi123@gmail.com

e-mail: volodymyr.polishchuk@uzhnu.edu.ua

e-mail: oleg.glukh@uzhnu.edu.ua

*Correspondence:

Natalia Svatiuk, Institute of Electron Physic of the National Academy of Sciences of Ukraine,

Ukraine, Uzhhorod, University st., 21.

e-mail: svatiuk@nas.gov.ua

How to cite this article:

Svatiuk, N., Roman, V., Pop, O., Simkanich, P., Polishchuk, V., Glukh, O., Pylypchynets, I. and Maslyuk, V. (2021). Low- background nuclear studies of uranium/thorium components of sediments of the Tisza River water basin. Acta Montanistica Slovaca. Volume 26 (4) 675-684

DOI:

https://doi.org/10.46544/AMS.v26i4.07

\begin{abstract}
The results of using nuclear-physical methods to study the characteristics of the terrestrial radioactivity of the sediments of the Tisza river water basin, particularly for uranium/thorium components, are presented. The results were obtained by lowbackground gamma-spectrometric measurements of the content of natural (natural isotopes $\left.\mathrm{U} / \mathrm{Th},{ }^{40} \mathrm{~K}\right)$ and artificial $\left({ }^{137} \mathrm{Cs}\right)$ radionuclides of sediments of the Borzhava River, one of the largest tributaries of the Tisza River. Regulations and procedures for establishing the studied areas' radiation parameters are considered:

- The sampling scheme

- The choice of isotope-marks

- Their characteristics and features of low-background gamma-spectrometric studies
\end{abstract}

According to the study results of samples of bottom sediments of the Borzhava River, information was obtained on spatial and seasonal changes in the specific activity of radionuclides of the uranium and thorium natural series nature-forming $\left({ }^{40} \mathrm{~K}\right)$ and technogenic isotopes $\left({ }^{137} \mathrm{Cs}\right)$. Data were obtained on the degree and nature of the imbalance in the equilibrium of daughter radionuclides of natural U/Th series content in the sediment samples. It is shown that the characteristics of terrestrial radioactivity make it possible to assess the geochemical indicators of the studied territories, the content, and the ratio of chemical elements $\mathrm{U} / \mathrm{Th} / \mathrm{K}$. The use of multidimensional statistical analysis allows establishing the degree of correlation between sampling points on the content of natural/technogenic radionuclides; latent factors that form the parameters of terrestrial radioactivity and indicate anthropogenic activity along the Borzhava riverbed. Systematic studies of this kind are essential for standardizing the parameters of terrestrial radioactivity parameters allow for certification and development of radiation maps of the Tisza River Basin.

\section{Keywords}

Tisza river reservoir, Borzsava, sediments, low-background measurements, radioisotopes, standards, $\mathrm{U} / \mathrm{Th} / \mathrm{K}$ abundance. 


\section{Introduction}

The mountain ranges of the Carpathians play an essential role in shaping the water and air regimes of Eastern and Central Europe and are the area where the Tisza, the largest river in Europe, originates (Maslyuk et al., 2013). Thus, the surface water resources of Transcarpathia are:

- a critical factor in the processes of microclimate formation.

- quality of human life.

- water and land use of the entire Eurocarpathian region.

The bottom sediments of the Carpathian water basins are natural markers of their quality and reflect the features and dynamics of chemical, microelement, and radionuclide composition changes, as they are formed under the influence of natural, in particular geochemical factors, as well as anthropogenic, meteorological and seasonal factors, due to the displacement of the soil banks of rivers, etc (Szabó et al., 2019).

First of all, the silts of mountain rivers reflect the characteristics of geochemical indicators of the territories adjacent to them to provide valuable information about the intensity and nature of human economic activity. The central part of Transcarpathian water resources consists of river runoff, which plays a significant role in the accumulation and movement of chemical components and isotopic composition of the surface layers of mountain slopes. However, the ecology balance for mountainous areas is very shaky. Anthropogenic loads here can lead to their significant changes. Mountains are a natural barrier to the spread of air masses and significantly affect the amount of deposited man-made waste, especially radionuclides from regions of high intensity of artificial factors (Symkanich al., 2016).

The natural potential of surface water self-purification is estimated by integrated indicators as very low in the mountain highland areas, low - in the foothills, medium - in the lowlands. Intensive leaching of radionuclides from the bedrock leads to the formation, in some areas, of radioactive water, which includes water containing radon-222, in the amount of more than $1,85 \cdot 10^{5} \mathrm{~Bq} / \mathrm{m}^{3}\left(5 \cdot 10^{-9} \mathrm{Ki} / \mathrm{l}\right)$, radium-226 - more than $1 \cdot 10^{-}$

${ }^{11} \mathrm{~g} / 1$, or uranium - more than $3 \cdot 10^{-5} \mathrm{~g} / 1$. The migration of radioactive elements with water occurs when moving radioactive particles with a water stream and moving soluble forms of radioactive substances in the area below the place of removal (Chau al., 2012). Another feature of mountain rivers is the uneven water flow, accounting for $75 \%$ of spring and autumn floods. Therefore, the results of long-term studies for fixed sampling points along the riverbed.

This paper presents the results of a 3-year radioisotope study conducted along the Borzhava River, one of the largest tributaries of the Tisza River. Regulations and procedures for establishing radiation parameters of the studied areas are considered: sampling scheme, selection of isotopes-labels for their characteristics, features of low-background gamma-ray spectrometric studies, and results of standards for content and ratio of massabundance of the chemical elements $\mathrm{U} / \mathrm{Th} / \mathrm{K}$ and the possibility of forecasting and migration territories.

\section{Methodology of silt sediment sampling of mountain rivers of the Carpathians and statistical processing of results}

It is known that radionuclide analysis allows solving the fundamental problems of the prevalence of chemical elements in the Earth's crust and studying the role of terrestrial radiation in human life (Masok al., 2018). In this paper, such studies were conducted on the example of samples of bottom sediments of the Borzhava riverbed, which is one of the important tributaries of the Tisza River.

The choice of isotopes-marks is an essential stage of identifying natural indicators of territories through the ratio of the basic components of uranium/thorium series, as well as ${ }^{40} \mathrm{~K}$, which has a cosmogenic origin (Concentrations of Uranium, Thorium, and Potassium in Sweden, 2005). The problem is the sufficiency of isotope sampling of basic and marker elements in the studied samples (rocks, soils, bottom sediments, vegetation) for the reliability of radiation diagnostics of the environment.

Gamma-active nuclides (GAN) such as ${ }^{214} \mathrm{Bi}$ and ${ }^{214} \mathrm{~Pb}$ can be used to determine standards for the content of radioactive series $U\left({ }^{238} \mathrm{U}\right)$. In the case of the equivalent of $\mathrm{Th}\left({ }^{232} \mathrm{Th}\right)$, it is possible to use the isotopes-labels ${ }^{212} \mathrm{~Pb},{ }^{212} \mathrm{Bi}$, and ${ }^{228} \mathrm{Ac}$ and the cosmogenic isotope ${ }^{40} \mathrm{~K}$ as markers of natural or geochemical characteristics of the region. To study the presence of equilibrium of $U / T h$ series isotopes, you can use data on the degree of equality of specific activities of isotopes ${ }^{214} \mathrm{Bi} /{ }^{214} \mathrm{~Pb},{ }^{212} \mathrm{~Pb} /{ }^{212} \mathrm{Bi}$. The intensity of technogenic factors can be analyzed by studying the content of ${ }^{137} \mathrm{Cs},{ }^{90} \mathrm{Sr}$. Other nuclear methods examine the values of activities of various uranium isotopes as ${ }^{235} \mathrm{U} /{ }^{238} \mathrm{U}$ to characterize the presence of nuclear objects, or nuclear power plants, or ${ }^{234} \mathrm{U} /{ }^{238} \mathrm{U}$, ${ }^{236} \mathrm{U} /{ }^{238} \mathrm{U}$, indicating the presence and technogenic impact spent nuclear materials.

Sampling plays an important role and is required to ensure the adequacy and reliability of the assessment of radioisotope indicators of the environment (Stochioiu et al., 2012). The selection program for bottom sediments should be in line with the objectives of the study. Thus, the selected samples should characterize the study area as much as possible. In addition, the mass of the sample taken should be sufficient to provide statistics on the measurement data obtained. Thus, samples are taken in areas with a stable dynamic balance between suspended 
particles and bottom sediments in watercourses with the fast flow typical of mountain rivers. Samples of bottom sediments by particle size distribution and river width were taken through one velocity vertical in the same area of the bottom of the water body to assess the dynamics of the content of pollutants in bottom sediments.

Samples of bottom sediments by particle size distribution and river width were taken through one velocity vertical in the same area of the bottom of the water body to assess the dynamics of the content of pollutants. Remarkable benchmarks on the riverbank recorded the position of the sampling points.

Samples were taken with a period that provides an opportunity to assess the degree of contamination of bottom sediments in the characteristic phases of their hydrological regime (Svatiuk et al., 2010). Therefore, to study the impact of geochemical and technogenic factors on the studied mountain regions of the Carpathians, one can use the special sampling scheme of the selected river: the first point should be chosen at the top of the mountain river, where human impact on the ecosystem is lowest; other points are selected downstream, where anthropogenic pressures increase, due to increasing population density, the amount of untreated wastewater discharged into the river, an increase in the number of uncontrolled landfills along the banks and a decrease in forest cover. A schematic representation of the location of sampling points (1T-4T) starting at the top of a mountain river is shown in Fig. 1.

Spatial position of sampling points

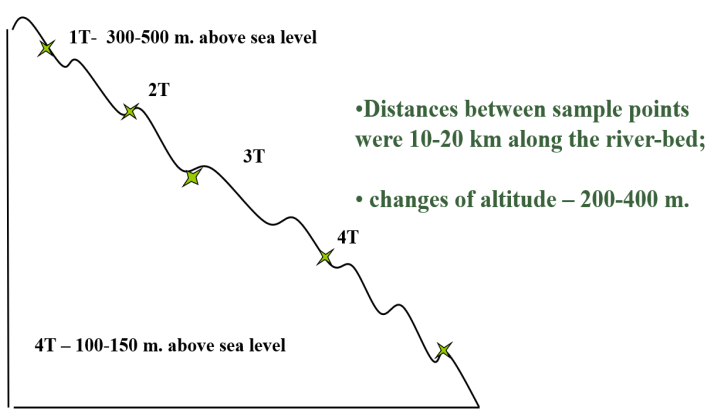

a)

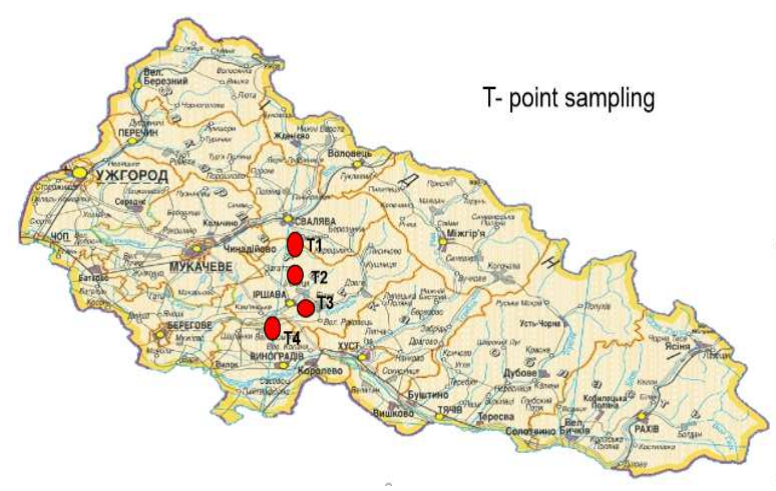

b)

Fig.1. a) - scheme of mountain relief and position of sampling points of silt, $1 T$ - 5T, along the riverbed of Borzhava river (conditionally); $b$ ) - the placement of these points (red circles) on the map of Transcarpathia

The position of the sampling points of the sediments was established using GPS navigation, and the distance between the sampling sites was $10-20 \mathrm{~km}$, taking into account the recommendations. The specified sampling points, Fig. 1b) are located near the settlements: T1 - Berezinka village, T2 - Kushnitsa village, T3 Dovhe village, T4 - Bilku village. This procedure allowed establishing the sources and ways of radionuclides entering the bottom sediments of the studied river. A sampling of river silt mud weighing more than 1500 - 2000 $\mathrm{g}$ was carried out at fixed points by hand from a depth of $0-15 \mathrm{~cm}$ using dredges. Samples were packaged, transported, and stored in plastic bags containing a packaging label indicating the sampling date, sample number, and information on the sampling place. When holding the selected material, it was necessary to preserve the composition of the samples. Therefore, the sample storage containers were sealed. The obtained samples of river sediments were dried at a temperature of $110^{\circ} \mathrm{C}$ in an oven to an air-dry state and stored in plastic bags. After grinding, foreign residues (plant roots, stones, glass, coal, animal bones, etc.) were removed from the samples, then sieved through a sieve with a hole diameter of $1 \mathrm{~mm}$ to obtain a homogeneous mass. Prepared samples of bottom sediments before radioisotope studies were placed in sealed containers for three weeks.

This procedure was able to ensure equilibrium conditions for radionuclides of series ${ }^{238} \mathrm{U}$ and ${ }^{232} \mathrm{Th}$. After that, the prepared sediment samples weighing 1-1.5 kg were taken into a Marinelli cup for radio spectroscopic analysis.

In the study of multi-parameter objects, which are samples of the environment, the question arises of the reliability of the results obtained based on a limited number of experiments (Davis et al., 2002). Therefore, for their interpretation, it is advisable to use the apparatus of multidimensional mathematical statistics. The problem is formulated as follows: let $N$ samples be taken as a result of radioecological monitoring. In each of them, the values of the properties $X_{i}$ were measured, where $I=1, k$, which are the values of the specific activities of the GAN of natural and men made origin. These features, formally, can be represented by components of multidimensional vectors. Then, the problem is reduced to cluster and factor analysis of $N$-arrays of $k$ dimensional vectors and establishing statistical regularities between them and their components.

It is known that cluster analysis involves selecting compact, similar, and distant in the aggregate of their properties from each other groups of objects, where the properties are the specific activities of the GAN. "Similarity" is understood here as the proximity of objects, formal vectors in the $k$-dimensional space of properties established in radioecological measurements. Using the clustering procedure of objects, one can 
obtain such a breakdown of the set of $k$-dimensional arrays of vectors that each sampling object belonged to one and only one group. The distances between objects of one group must be much smaller than the distances $L$ between objects of other groups. The values of the properties that characterize the objects of one cluster should be close to each other. The values of the properties that describe the objects of different clusters are significantly different from each other. Determination of the distances between points of multidimensional space gives one the ability to allocate compactly located groups of objects.

Such a procedure can solve the problem of their multidimensional clustering irrespective of the dimension of a system.

Factor analysis is another form of multidimensional statistical analysis (Child et al., 2006). It allows you to identify and investigate the strength of the impact of various latent indicators that form the radiation characteristics of silt. It is necessary to take into account several latent factors in radioecological studies. One of them is natural causes such as the propagation and nuclear transformations of daughter isotopes of the ${ }^{238} U$ or ${ }^{232} \mathrm{Th}$ series. One can also mention the presence of cosmogenic GAN, geochemical characteristics of the region, et al. Among the latent factors related to the features and intensity of anthropogenic activity for this area are nuclear and thermal energy, nuclear technology in medicine and industry. In our case, the factor analysis investigates the internal structure of the correlation matrices of properties formed by arrays of specific radioactivities of the GAN obtained in low-background experiments. The factor analysis solves the following tasks: establishing the number of active factors and their relative intensity; establishing the characteristic structure of factors, that is, the extent to which the action of a factor affects the presence and magnitude of a certain physical property for the studied sampling points and, finally, identifying the factor structure of the studied properties, or establishing the shares of each factor on the value of a property object. These factors are hidden or latent and cannot be directly measured. Methods for identifying their effects on the environment are the essence of factor analysis in radioecology studies.

\section{Methods of low-background investigation to assess the geochemical parameters of the studied areas}

Establishing the radioisotope composition of the object of study requires the use of nuclear physics research methods. The radioisotope composition is determined in the low-background studies of the natural activity of environmental samples.

All of them contain a wide range of radionuclides, and their formation is due to the action of various factors of natural and man-made origin. Natural radioactivity is based on the presence in natural samples of products of radioactive decay of natural series of uranium and thorium. Thus, both nuclear and geochemical processes form it. As a rule, such radioactivity is determined by the content of mineral grains of different nature in environmental samples, as well as fragments of primary rocks, which determine their chemical and isotopic composition. In addition, leaching and precipitation of radionuclides under rain and groundwater determine the distribution of nuclide activity by soil depth or along riverbeds.

In this article, radionuclide identification was made by the $\gamma$-spectroscopy technique. The multichannel amplitude analyzers used the cooled $175 \mathrm{~cm}^{3} \mathrm{HPGe}$ and $100 \mathrm{~cm}^{3} \mathrm{Ge}<\mathrm{Li}>$ detectors. The low-background measurements were carried out in the shielded environment that reduces external gamma-radiation 100 times. The detector was shielded by copper $(8 \mathrm{~mm})$, cadmium $(1 \mathrm{~mm})$, aluminum $(3 \mathrm{~mm})$, and lead $(95 \mathrm{~mm})$ layers to reduce the influence of the gamma-ray background. The conditions for the gamma-spectrometric measurements, such as channel drift and spectrum resolution, were controlled during the investigations and stabilization of the low-background measures as moisture content, air convection, et al. (Potoki et al., 2018). The series of measurements verifying low background levels was performed periodically (from 4 to 30 hours) and showed stability.

There are some essential factors that determine the time of gamma spectrometric measurements as low background conditions and the sensitivity and accuracy of nuclear equipment. In our case, such verification gives us the range of $5-50$ thousand seconds for soils' natural gamma-activity counting. Within this range, the measuring time of $5000 \mathrm{~s}$ was finally established for measuring the silt sediments samples.

Data on the specific activities of the GAN, obtained in low-background experiments, allow us to assess the degree of age balance between members of the natural radioactive series $U$, Th. Since the initial amounts of the parent isotope ${ }^{232} \mathrm{Th},{ }^{238} \mathrm{U}$ are unknown. It is essential to establish the presence of equilibrium either within the radioactive series or between these series (Pop et al., 2019). Thus, for the ${ }^{232} \mathrm{Th}$ radioactive series, the equilibrium should be expected for ${ }^{212} \mathrm{~Pb}-{ }^{208} \mathrm{Tl}$ nuclides and the ${ }^{228} \mathrm{Ac}-{ }^{212} \mathrm{~Pb}$ conversion chains (intermediate ${ }^{228} \mathrm{Th}$ with $T_{1 / 2}=1.91$ years). In the case of natural series ${ }^{238} \mathrm{U}$, and it can say that $\mathrm{GAN}{ }^{214} \mathrm{~Pb}-{ }^{214} \mathrm{Bi}$ are in equilibrium. On the other hand, it is difficult to establish nuclear balance for the ${ }^{226} \mathrm{Ra}-{ }^{214} \mathrm{~Pb}$ chains due to the contribution of $186 \mathrm{keV}$ activity from the ${ }^{235} \mathrm{U}$ line as the most probable, as well as the removal of highly mobile radon ${ }^{222} \mathrm{Rn}\left(T_{1 / 2}=3.82\right.$ days $)$, the decay product of the parent ${ }^{226} \mathrm{Ra}\left(T_{1 / 2}=1600\right.$ years $)$. 
Knowing the abundance of isotopes in the natural mixture and the values of specific activities of radionuclides ${ }^{232} \mathrm{Th},{ }^{238} \mathrm{U}$ series, as well as ${ }^{40} \mathrm{~K}$, there is a promising method to determine the content of corresponding chemical elements.

Such a procedure can only be done when the correlation of the radioactivities of daughter isotopes of the studied samples exists.

It is known that data on the content of components of long-lived radionuclides $\mathrm{U}$, Th, and $\mathrm{K}$ are important geochemical characteristics of the region (Dikiy et al., 2017). In addition, their content is also determined by the territorial parameters of the heat-flow data, which generate unstable isotopes during nuclear transformations.

To assess the atom-abundance of samples' uranium-thorium components is necessary to establish the ratio of their specific radionuclide activities, determined in low-background experiments, $\frac{A^{(T h)}}{A^{(U)}}$. The next step is to determine the amounts of these radionuclides by the number of atoms, using the formula:

$$
\frac{N_{T h}}{N_{U}} \cong \frac{T_{1 / 2}^{(T h)}}{T_{1 / 2}^{(U)}} * \frac{A^{(T h)}}{A^{(U)}}
$$

Here $\frac{T_{1 / 2}^{(T h)}}{T_{1 / 2}^{(U)}}$ is the ratio of the half-lives of the isotopes ${ }^{232} \mathrm{Th}$ and ${ }^{238} \mathrm{U}$, equal to 3.14 . Note that the content of the isotope ${ }^{232} \mathrm{Th}$ in the chemical element thorium is near $100 \%$, and the isotope ${ }^{238} \mathrm{U}$ in uranium is $99.27 \%$. Therefore, the ratio of the amounts of chemical elements thorium and uranium in the studied samples is determined with high accuracy by equation (1).

The same ratios for the activities of ${ }^{232} \mathrm{Th}$ and ${ }^{40} \mathrm{~K}$ in the test samples $\frac{A^{(T h)}}{A^{(40 K)}}$ make it possible to determine the quantities for these radionuclides by the number of atoms, using the formula:

$$
\frac{N_{T h}}{N_{40 K}} \cong \frac{T_{1 / 2}^{(T h)}}{T_{1 / 2}^{(40 K)}} * \frac{A^{(T h)}}{A^{(40 K)}},
$$

The ratio for the half-lives of the isotopes ${ }^{232} \mathrm{Th}$ and ${ }^{40} \mathrm{~K}$ is constant and equal to 11.66 . However, the isotope ${ }^{40} \mathrm{~K}$ content in the chemical element potassium is much lower than in previous isotopes and is $0.017 \%$. In this case, to establish the ratio of the amounts of chemical elements thorium and potassium in the studied samples should be corrected for the content of the isotope ${ }^{40} \mathrm{~K}$ in natural $\mathrm{K}$, then.

The ratio for the half-lives of the isotopes ${ }^{232} \mathrm{Th}$ and ${ }^{40} \mathrm{~K}$ is constant and equal to 11.66 . The content of the isotope ${ }^{40} \mathrm{~K}$ in the chemical element potassium is much lower than in previous isotopes and is $0.017 \%$. In this case, to establish the ratio of the amounts of chemical elements thorium and potassium $\frac{N^{(T h)}}{N^{(K)}}$ in the studied samples should be corrected for the content of the isotope ${ }^{40} \mathrm{~K}$ in natural $\mathrm{K}$, then.

$$
\frac{N^{(T h)}}{N^{(K)}}=\frac{N_{T h}}{N_{40 K}} * 5882
$$

\section{Results and discussion}

For radioisotope research of silt, eight expeditions were carried out along the Borzhava River. The obtained data, table 1, allowed us to get the average indicators (standards) of the specific content of GAN for each of the sampling points, T1 - T4, Fig.1, and the entire riverbed for the whole of the observation period. As mentioned above, as a marker of the content of the uranium component isotope ${ }^{214} \mathrm{Bi}$, thorium, respectively, $-{ }^{212} \mathrm{~Pb}$. In addition, it is also essential to control the content of the cosmogenic isotope ${ }^{40} \mathrm{~K}$. Then as a marker of technogenic factors, in particular, the activities of nuclear power plants may be the content of ${ }^{137} \mathrm{Cs}$. In addition to the averaged indicators, the analysis of the obtained data allows investigating the features of the spatial distribution of GAN, the presence of similarity of sampling points on the content of GAN of natural and technogenic origin.

Table 1. The average content (standards) of the GAN in the samples of silt of the Borzhava River during the 3rd annual monitoring as for the selected sampling points T1 - T4, as well as the generalized value for the entire riverbed

\begin{tabular}{|c|c|c|c|c|}
\hline № sampling (settlement) & $\begin{array}{c}\text { Specific activity } \\
{ }^{40} \mathrm{~K}(\mathrm{~Bq} / \mathrm{kg})\end{array}$ & $\begin{array}{c}\text { Specific activity }{ }^{137} \mathrm{Cs} \\
(\mathrm{Bq} / \mathrm{kg})\end{array}$ & $\begin{array}{c}\text { Specific activity }{ }^{214} \mathrm{Bi} \\
(\mathrm{Bq} / \mathrm{kg})\end{array}$ & $\begin{array}{c}\text { Specific activity }{ }^{212} \mathrm{~Pb} \\
(\mathrm{~Bq} / \mathrm{kg})\end{array}$ \\
\hline T1 - Berezinka village & 340 & 3,9 & 22,1 & 20,2 \\
\hline T2 - Kushnitsa village & 307,9 & 3,9 & 1 & 21,7 \\
\hline T3 - Dovhe village & 292,9 & 3,6 & 19,3 & 17,9 \\
\hline
\end{tabular}




\begin{tabular}{|c|c|c|c|c|}
\hline T4 - Bilku village & 290 & 3,5 & 17,9 & 17,4 \\
\hline Dispersion & $\mathbf{1 6 , 2 5}$ & $\mathbf{0 , 1 7}$ & $\mathbf{1 , 7 5}$ & $\mathbf{1 , 6 5}$ \\
\hline Standard & $\mathbf{2 9 7 , 4}$ & $\mathbf{3 , 7 2}$ & $\mathbf{1 9 , 7}$ & $\mathbf{1 9 , 1}$ \\
\hline
\end{tabular}

Table 2 shows the results of using correlation analysis to establish the statistical proximity of sampling points, Fig. 1, along the Borzhava River, through a matrix of pairwise correlations of their features - specific activities of GAN series ${ }^{238} \mathrm{U}$ (a) and ${ }^{232} \mathrm{Th}(\mathrm{b})$. The analysis shows a weakening of the correlation dependence of the specific content of GAN, starting from the sampling point T1, in the upper reaches of the river. The decline of the correlation between the sampling points $\mathrm{T} 2-\mathrm{T} 3$, in comparison with $\mathrm{T} 1-\mathrm{T} 2$ for both uranium and thorium components, may indicate the influence of anthropogenic factors. According to Table 2, this trend is more pronounced for the members of the uranium series due to their greater chemical mobility in the aquatic environment (Badawy et al., 2018). A more detailed study of the conditions of radioactive equilibrium disturbance of genetic genes of uranium/thorium series requires greater measurement statistics and considering the conditions of formation of chemical and trace element composition of bottom sediments.

Table 2. Matrix of pair correlations of sampling points along the Borzhava riverbed using data from the specific activity of natural GAN

\begin{tabular}{c|cccc}
\multicolumn{5}{c}{${ }^{214}$ Bi, uranium series } \\
\hline & №1 & №2 & №3 & №4 \\
\hline №1 & 1 & 0,92 & 0,86 & 0,78 \\
№2 & 0,92 & 1 & 0,67 & 0,89 \\
№3 & 0,86 & 0,67 & 1 & 0,63 \\
№4 & 0,78 & 0,86 & 0,63 & 1
\end{tabular}

\begin{tabular}{c|cccc}
\multicolumn{5}{c}{${ }^{212}$ Pb, thorium series } \\
\hline & №1 & №2 & №3 & №4 \\
\hline №1 & 1 & 0,32 & 0,2 & 0,23 \\
№2 & 0,32 & 1 & $-0,28$ & 0,62 \\
№3 & 0,2 & $-0,28$ & 1 & 0,29 \\
№4 & 0,23 & 0,62 & 0,29 & 1
\end{tabular}

These conclusions can be supplemented by cluster analysis results, Fig. 2, using the GAN of natural and technogenic origin of the Borzhava river basin. The results are essential for establishing their spatial patterns of distribution and accumulation. As mentioned above, in cluster analysis, the degree of similarity of sampling points is inversely proportional to the distance $L$ between their objects in the feature space related to the data of radioecological measurements. So, fig. 2 a) and b) confirms the conclusion about the natural prevalence of GAN of the uranium/thorium series and ${ }^{40} \mathrm{~K}$, as they show less value of the union parameter $L$, that is, greater statistical proximity of the initial, 1 and 2 sampling points. Moreover, radioactive signs of uranium/thorium components, fig. 2 b) are more important, providing a smaller value of $L$ for the association of sampling points than the content of natural radionuclide ${ }^{40} \mathrm{~K}$, Fig. 2a). This fact may indicate the statistical nature of the distribution of uranium/thorium components and the ${ }^{40} \mathrm{~K}$ isotope along the mountain riverbed. Therefore, the correlation between sampling points weakens with increasing distance between them.

Cluster analysis of sampling points for specific content in the sediments of technogenic GAN, an example of ${ }^{137} \mathrm{Cs}$, shows a more significant sign similarity in the lower sampling points, 3 and 4 . This result suggests that the source of technogenic ${ }^{137} \mathrm{Cs}$ are highlands of the Carpathians, where its concentration is higher, Table 1; however, the accumulation is random in interaction with airflows. On the other hand, lowland areas of mountain rivers accumulate their content. Furthermore, there is an averaging of specific activities, leading to more similar characteristics and statistical proximity between sampling points 3 and 4 .

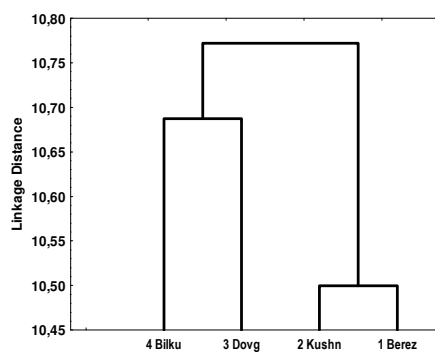

a)

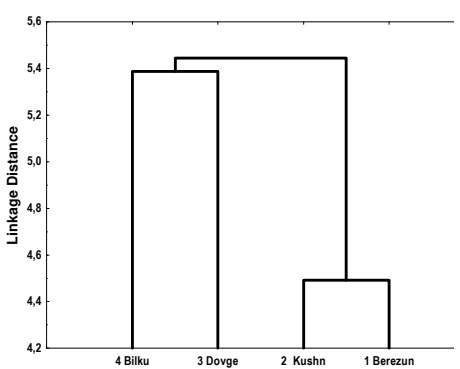

b)

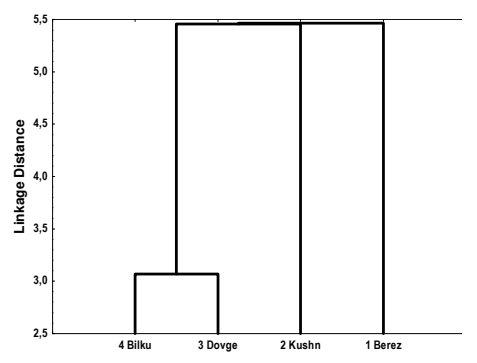

c)

Fig. 2. Dendrograms of cluster analysis assess the statistical proximity of sampling points along the Borzhava riverbed by content: a) $40 \mathrm{~K}, \mathrm{~b}$ ) - by content of daughter GAN of the U/Th series, c) - content of technogenic ${ }^{137} \mathrm{Cs}$. A lower value of the aggregation parameter indicates a greater degree of statistical proximity of the sampling points.

Since the characteristics of terrestrial radioactivity are due to technogenic and natural influences, the geochemical state of the studied areas is appropriate to use factor analysis to determine their effects. Table 3 shows the data of 3-factor analysis to establish their significance for the spread of the studied GAN. The value of 
the factor's load indicates the weight and influence of the factor itself and its sign, plus or minus - the nature of the impact. The factor loads given in Table 3 are set for each sampling point and GAN grade understudy: here, the designation $A \_i$ refers to the specific activities of the radionuclide grade $A$, respectively, ${ }^{214} \mathrm{Bi}$ (uranium label), ${ }^{212} \mathrm{~Pb}$ (thorium label), ${ }^{40} \mathrm{~K},{ }^{137} \mathrm{Cs}$. The index $i=1-4$ refers to the number of four sampling points $\mathrm{T} 1$ - T4. Significant factor loads with a reliability of more than $90 \%$ are highlighted in bold in Table 3 .

As can be seen, factor 1 with a weight of $48.17 \%$ with a strong negative impact determines the distribution of uranium isotopes for all sampling points, less significant its impact, also with a negative relationship - for thorium isotopes. The exception is the point T4, where the formation of these isotopes occurs under conditions of interference of influences of several factors, positive and negative, in the degree of impact. Factor 1 is also dominant, with a negative effect on forming the natural isotope ${ }^{40} \mathrm{~K}$ content in the sludge. In the lower point T4, in addition to this factor, the distribution of ${ }^{40} \mathrm{~K}$ is influenced by a positive factor 3 , the total weight of which is $10.23 \%$. Finally, factor 1 plays a significant role in forming the content of the technogenic component ${ }^{137} \mathrm{Cs}$. As shown from table 3 , this factor is decisive with a negative effect on the formation of ${ }^{137} \mathrm{Cs}$ content for point $\mathrm{T} 2$. In contrast, for other points, T1, T3, T4 also have a positive impact of factor $2(12.71 \%)$ and partly factor $3(10$, $23 \%$ ) with a negative sign, point $\mathrm{T} 1$.

Table 3. Values of factor loads of specific activities of GAN of natural and technogenic origin are presented for different sampling points, $T 1-T 4$.

\begin{tabular}{|c|c|c|c|}
\hline & Factor -1 & Factor -2 & Factor -3 \\
\hline K40_1 & $\mathbf{- 0 , 7 7 0 7 8 1}$ & 0,142411 & $-0,176506$ \\
\hline K40_2 & $\mathbf{- 0 , 6 7 0 9 8 0}$ & 0,117316 & $-0,418291$ \\
\hline K40_3 & $\mathbf{- 0 , 8 1 5 4 0 1}$ & 0,308480 & 0,169781 \\
\hline K40_4 & $-0,540722$ & 0,088182 & $\mathbf{0 , 6 7 4 7 7 1}$ \\
\hline Cs137_1 & $-0,436352$ & $\mathbf{0 , 5 3 9 1 2 5}$ & $-0,479406$ \\
\hline Cs137_2 & $\mathbf{- 0 , 6 1 0 2 0 0}$ & $-0,407763$ & 0,037414 \\
\hline Cs137_3 & $-0,549643$ & $\mathbf{0 , 5 7 9 2 3 7}$ & $-0,280720$ \\
\hline Cs137_4 & $-0,489401$ & $\mathbf{0 , 6 2 8 4 4 7}$ & 0,054000 \\
\hline Pb212_1 & $\mathbf{- 0 , 8 7 5 6 5 1}$ & $-0,176078$ & $-0,054431$ \\
\hline Pb212_2 & $\mathbf{- 0 , 7 3 7 2 4 1}$ & $-0,207168$ & $-0,357193$ \\
\hline Pb212_3 & $\mathbf{- 0 , 6 3 8 5 9 2}$ & 0,228845 & 0,445814 \\
\hline Pb212_4 & $-0,327176$ & 0,387426 & 0,480655 \\
\hline Bi214_1 & $\mathbf{- 0 , 9 2 5 8 2 3}$ & $-0,324845$ & $-0,047356$ \\
\hline Bi214_2 & $\mathbf{- 0 , 7 7 1 1 5 7}$ & $-0,400593$ & $-0,139765$ \\
\hline Bi214_3 & $\mathbf{- 0 , 8 7 5 2 7 5}$ & $-0,240398$ & 0,213003 \\
\hline Bi214_4 & $\mathbf{- 0 , 7 4 6 9 8 1}$ & $-0,329280$ & 0,082831 \\
\hline Weight factors, & 448.17 & 12,71 & 10,23 \\
\hline \% & & & \\
\hline
\end{tabular}

Figure 3 presents the 2D characteristics of the grouping of the studied radionuclides for different combinations of 3 factors that determine the patterns of their statistical clustering. First of all, it is possible to establish a significant influence of factor 1. Then, the combination of factor 2 leads to an apparent clustering of GAN by features - technogenic or natural nuclide. Moreover, in the latter case, these factors separate the uranium-thorium components of natural radioactivity in silt and ${ }^{40} \mathrm{~K}$. On the other hand, the combination of factors 1 and 3, Fig. 3b) somewhat weakens the effect of statistical clustering of GAN due to the above interference, for example, different impact on the content of the thorium component. And Fig. 3c) relatively insignificant factors 2 and 3 restore the initial character of clustering by demonstrating statistical correlations between GAN of natural and technogenic origin in silt samples.

By interpreting these results, one should bear in mind that in the state of radioactive equilibrium, for example, in samples of rocks or minerals, the activities of natural uranium-thorium series are close and are determined by the presence of parent radionuclides ${ }^{238} \mathrm{U} /{ }^{232} \mathrm{Th}$ series. In an open system, such as annual silt, radioactive equilibrium can be disturbed by water leaching, mechanical movement, or chemical reaction of atoms of some members of a series relative to others (Titaeva et al., 1984). However, the significant imbalance is possible in only two cases: when the isotope atom is moved to a distance greater than the size of the system and for a timeless than that required to restore equilibrium. In our case, the presence of clustering of GAN serving as marks of uranium-thorium series along the riverbed can serve as a characteristic of the chemical and geological features of the region where it occurs. Therefore, factor 1 may be responsible for the nuclear-physical properties of the studied isotopes, their belonging to certain natural series, or the composition of natural potassium. Factor 1 can also be accountable for the nuclear-physical properties of the studied isotopes, their belonging to certain natural series, or the composition of natural potassium. This factor can be responsible for their accumulation in the compositions as potassium minerals monazites with impurities of actinides. All these materials provide the conditions of quasi-equilibrium of daughter isotopes of natural series in the sample. Factors 2 and 3 may be responsible for the geochemical characteristics of the region, hydrodynamic parameters of mountain rivers, climatic, spatial, and seasonal patterns of the study region. 


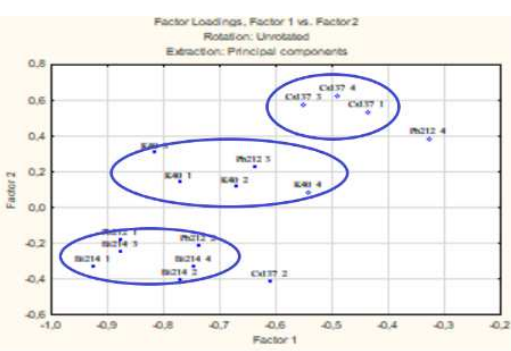

a)

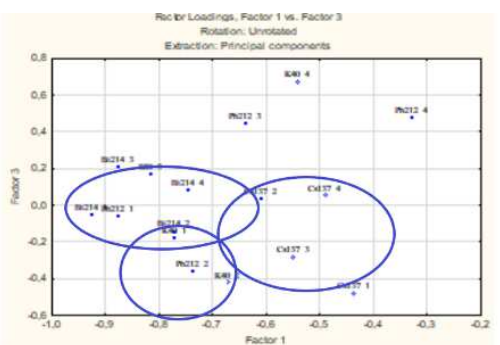

b)

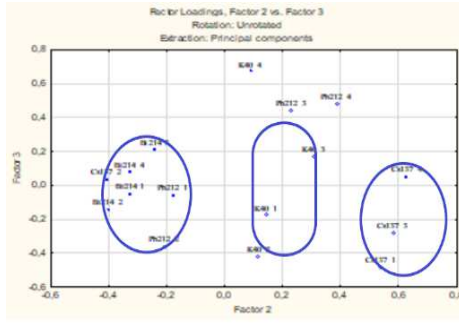

c)

Fig. 3. $2 D$ graphs of factor loads, demonstrating the different nature of the statistical grouping of GAS of natural and man-made origin in the silt of the Borzhava River: a) when choosing factors 1, 2; b), respectively, 1, 3, and c), - factors 2 and 3. Weight of factors 1 3 , respectively: $48.17 \%, 12.71 \%$ and $10,23 \%$

As mentioned above, the study of terrestrial radioactivity under the condition of quasi-equilibrium of the content of daughter isotopes of natural ${ }^{232} \mathrm{Th},{ }^{238} \mathrm{U}$ series, and ${ }^{40} \mathrm{~K}$ allows estimating the content of chemical elements in the studied areas due to the value of their specific activities. However, to use formulas (1) - (3) requires a significant array of terrestrial radioactivity monitoring data to establish the degree of correlation between their values in the studied samples. Fig. 4 presents the study results of correlations between the specific content of uranium-thorium a) and potassium-thorium components b) in the sludge.

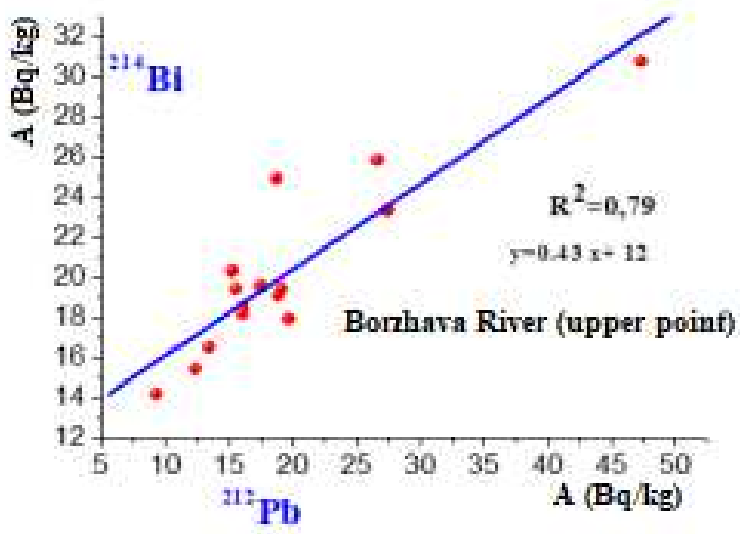

a)

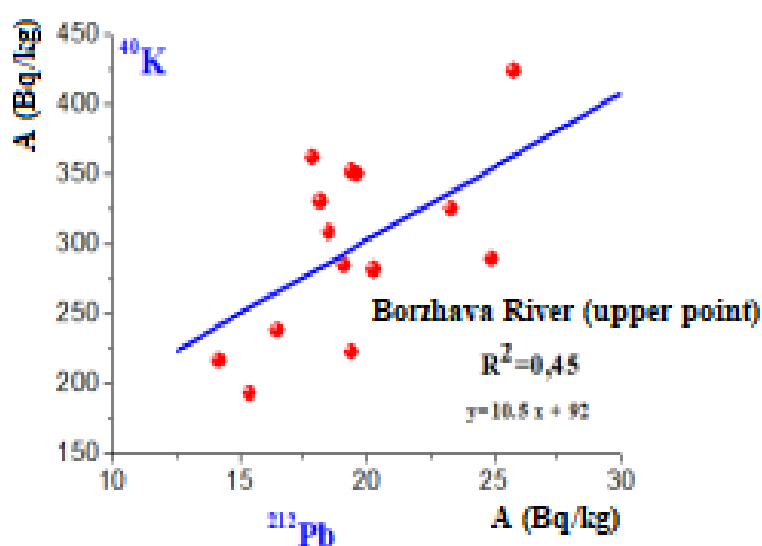

b)

Fig. 4. Correlation dependences on the specific content of uranium-thorium a) and potassium-thorium components b) samples of siltstones of the Borzhava riverbed. The data in a) -b) correspond to the upper sampling point T1.

Different degrees of correlations between the contents of these GANs are noteworthy: sufficient significance can be said for uranium-thorium components, the same dependences for potassium-thorium components are less pronounced. This result is due to the nature of these radionuclides and the possible influence of several factors: geochemical parameters of the region and human activity. Using the research results, fig. 4 and formulas (1) - (3), it is possible to estimate the Clark ratios of the quantities of chemical elements by the number of atoms:

$$
\mathrm{U}: \mathrm{Th}: \mathrm{K}=1: 7.2: 6532 \text { at. } \%
$$

The data on the content and ratio of the basic elements $\mathrm{U}$, Th, $\mathrm{K}$ in the Earth's crust differ using different measurement techniques and the geographical location of sampling points. Due to the low concentration, their content is determined in $\mu \mathrm{g} / \mathrm{kg}$ or ppm (the part per million), $1 \%=10000 \mathrm{ppm}$. Moreover, units are used to relate to both mass and atomic content, as we showed in (4). And although the average Th / U values for the Earth's crust are 2-5, studies show a wider range of 1.5 - 11 (Chau et al., 2012, Masok et al., 2018), for example, in recent studies of rocks. The results obtained in (4) are close to the data (Tzortzis et al., 2004, Vasconcelos et al., 2009) and especially (Dikiy et al., 2017) where similar methods of soil research were used, - 1: 5,62: 4320.

\section{Conclusion}

Radioisotope study of sediments of the Borzhava River allows establishing the average indicators or standards of the GAN of natural, particularly uranium/thorium components and man-made origin of the water basin of the Tisza River. In addition, mountain river sediments provide valuable information about large adjacent 
areas' chemical and radionuclide composition, geochemical characteristics, and the intensity of anthropogenic, meteorological, and seasonal factors. The importance of low-background gamma-spectrometric experiments for this type of geochemical research is shown. The obtained results are important for monitoring the ecological condition of the Eurocarpathian region, for which the Tisza River is the largest water resource. The peculiarities of their values for isolated mountainous areas of the Carpathians, the nature of their change for mountainous and lowland areas of the Tisza river basin are shown. The research shows GAN's spatial distribution and migration features of natural and man-made origin along riverbeds.

The obtained results are relevant, particularly about the disturbance of uranium/thorium component of silts with river channel altitude, leaching technogenic GAN from high horizons, and their accumulation in lowland mountain river areas. It was shown that according to cluster and factor analysis, there are correlations between sampling points, natural factors' influence, and anthropogenic activity along the Borzhava riverbed. The experiments were conducted allowed one to obtain the first estimations of geochemical parameters, the ratio of the uranium-thorium-potassium components of sediments for the Borzhava River. The obtained data of radioisotope research allow model the processes of migration of GAN from bottom sediments into the soillandscape of territories, which will allow to predict the future state of the adjacent regions and carry out certification of the studied environment.

\section{References}

Badawy, W, M., Duliu, O. G.,. Frontasyeva, M. V., Samman, H. El \& Faanhof A. (2018). Environmental radioactivity of soils and sediments: Egyptian sector of the Nile valley, Isotopes in Environmental and Health Studies, 54:5, 535-547, DOI: 10.1080/10256016.2018.1482292

Chau, N. D., Lucyna, R., Nowak J., Jodłowski P. (2012). Radium isotopes in the Polish Outer Carpathian mineral waters of various chemical composition. Journal of Environmental Radioactivity. Vol. 112, pp. 38-44., DOI:org/10.1016/j.jenvrad.2012.03.010

Child, D. (2006). The Essentials of Factor Analysis (3rd ed.). Continuum International, ISBN 978-0-8264-80002.

Concentrations of Uranium, Thorium and Potassium in Sweden. (2005). ISSN 0282-4434. SSI rapport: 2005:04.

Davis, J.C., 2002. Statistics and Data Analysis in Geology. 3rd editionn. John Wiley \& Sons Inc. 656 p.

Dikiy, N. P., Lyashko, Yu. V, Medvedeva, E. P., Medvedev, D. V, Parhomenko, Yu. G., Fedorets, I. D. (2017). The content of natural radioactive isotopes in soil of Kharkov region. Problems of atomic science and technology. Series: Nuclear Physics Investigations, 3 (109). ISSN 1562-6016. pp. 55-59.

Masok, F. B., Masiteng, P. L., Mavunda, R. D., Maleka, P. P., Winkler, H. (2018). Determination of uranium and thorium concentration and gross alpha and beta activity measurement in top soil samples from Richards Bay, South Africa. Journal of Radiation Research and Applied Sciences. Vol. 11, Issue4. DOI: org/10.1016/j.jrras.2018.04.003

Maslyuk, V., Svatyuk, N., Stets, M., Frontasyeva, M., Parlag, O. (2013). Statistical regularities in the distribution of radionuclides in sediments of Transcarpathia mountain rivers. Journal of Environmental Radioactivity. V. 117, p. 9-12, DOI:10.1016/j.jenvrad.2012.04.016.

Pop, O. and Maslyuk, V. (2019) Applications of the uranium's set of isotopes for nuclear dating: the MonteCarlo method. Radiochimica Acta, vol. 107, no. 3, pp. 207-213. https://doi.org/10.1515/ract-2018-3001

Potoki, I. Parlag, O., Lengyel, A, Pylyphynets, I., Maslyuk, V. (2018). An empirical function of energy and distance for the gamma-ray efficiency of a HPGe detector. INPPAS, P. 28. DOI:10.18428/TREICEP2018.

Szabó, S., Szopos, N. M., Bertalan-Balázs, B., László, E., Milošević, D. D., Conoscenti, C., \& Lázár, I. (2019). Geospatial analysis of drought tendencies in the Carpathians as reflected in a 50-year time series. Hungarian Geographical Bulletin, 68(3), 269-282. https://doi.org/10.15201/hungeobull.68.3.5.

Stochioiu, A., Luca, A., Sahagia, M., Margineanu, Tudor, I. (2012). Quality assurance for measurements of the radioactivity in the area of the "Horia Hulubei" National Institute for Physics and Nuclear Engineering, IFIN-HH. Journal of Environmental Radioactivity. Vol. 112, pp. 4-7.

Svatiuk, N.I., Symochko, D.M. (2010). Radioecology of Transcarpathian mountain Rivers: Time and Spatial Correlations. Nuclear Physics and Accelerators in Biology and Medicine. Fifth International Summer School edited by A.Dubnichkova, S. Dubnichka, C. Granja, C. Leroy, I. Stekl. AIP Conference Proceedings; 1/5/2010, Vol. 1204. Issue 1, pp. $263-264$.

Symkanich, O., Maslyuk, V., Svatyuk, N., Parlag, O., Shpenik, O., Sukharev, S. (2016). Radionuclide monitoringin Transcarpathian region: the role natural and antropogenic factors. Acta facultatis studiorum humanitatis et naturae universitatis presoviensis. Natural sciences. Biology-ecology. Preshov, Slovac republic. Vol. XLIII ISBN 80-8068-249-6. pp. $11-120$. 
Titaeva, N.A., Taskaev, A.I. (1984). Migration of heavy natural radionuclide in a humid zone. Leningrad, Nauka, 232 p.

Tzortzis, M., Tsertos, H. (2004). Determination of thorium, uranium, and potassium elemental concentrations in surface soils in Cyprus. Journal of Environmental Radioactivity. 77 (3): 325-38, DOI: 10.1016/j.jenvrad.2004.03.014

Vasconcelos, D,C., Oliveira, A.H., Silva, M.R., Penna, S.R,. Santos, T.O, Pereira, C., Rocha, Z. and. Menezes, B.C. (2009). Determination of uranium and thorium activity concentrations using activation analysis in beach sands from extreme south Bahia, Brazil. International Nuclear Atlantic Conference. INAC 2009, Rio de Janeiro, RJ, Brazil. ISBN: 978-85-99141-03-8. 